\title{
The Peripheral Metabolism of Triiodothyronine in
}

\section{Normal Subjects and in Patients with Hyperthyroidism}

\author{
Kenneth A. Woeber, Richard J. Sobel, Sidney H. Ingbar, and \\ KENNETH STERLING \\ From the Thorndike Memorial Laboratory, Second and Fourth (Harvard) \\ Medical Services, Boston City Hospital, and the Department of Medicine, \\ Harvard Medical School, Boston, Massachusetts; and the Protein Research \\ Laboratory, Bronx Veterans Administration Hospital, and the Department \\ of Pathology, Columbia University College of Physicians and Surgeons, \\ New York 10032
}

\begin{abstract}
A B S T R A C T In order to assess the contribution of 3.3',5-triiodo-L-thyronine $\left(\mathrm{T}_{3}\right)$ to overall thyroid hormone economy, conjoint measurements of the kinetics of peripheral $T_{3}$ metabolism and the total concentration of $T_{3}$ in serum were made in a group of normal subjects and in a group of patients with hyperthyroid Graves' disease. As judged from the disappearance of trichloroacetic acid-precipitable ${ }^{131} \mathrm{I}$ from serum after a single intravenous dose of labeled $T_{3}$, the following mean values were obtained in the normal subjects: volume of distribution, 43 liters or 0.62 liter $/ \mathrm{kg}$; fractional turnover rate, $52 \%$ per $24 \mathrm{hr}$; clearance rate, 22.3 liters $/ 24 \mathrm{hr}$; and absolute disposal rate, $60 \mu \mathrm{g} / 24 \mathrm{hr}$. In the patients with untreated hyperthyroidism, values for all these functions were greatly increased. After treatment, the volume of $T_{3}$ distribution returned to normal but the fractional turnover rate remained abnormally rapid.
\end{abstract}

\section{INTRODUCTION}

The increasing evidence that 3,3',5-triiodo-L-thyronine $\left(T_{3}\right)$ is important relative to L-thyroxine $\left(T_{4}\right)$ in normal thyroid hormone economy and in iodine metabolism makes essential an appreciation of the quantitative aspects of the kinetics of peripheral $\mathrm{T}_{3}$ metabolism. Previously reported data are relatively scant and, in some respects, conflicting (1-8). Although some data concerning the total concentration of $T_{3}$ in serum are available (9-11), conjoint measurements of $T_{3}$ concentration and of the kinetics of $\mathrm{T}_{3}$ turnover in the same in-

This work was presented in part at the Third International Congress of Endocrinology in Mexico City in July, 1968.

Received for publication 20 June 1969 and in revised form 27 October 1969. dividual, to make possible measurements of the absolute rate of disposal of hormone, have not been made. Data are particularly scant concerning the peripheral metabolism of $T_{3}$ in patients with hyperthyroidism $(5,12)$, a disorder in which recent measurements of the total concentration of $T_{3}$ in serum suggest that this hormone may play a preponderant role. Accordingly, we undertook to study the peripheral metabolism of $T_{3}$ and its absolute rate of disposal in a group of normal subjects and in a group of patients with hyperthyroid Graves' disease.

\section{METHODS}

Studies of the peripheral metabolism of ${ }^{181} \mathrm{I}$-labeled $\mathrm{T}_{3}$ were carried out in seven normal subjects and in seven patients with hyperthyroid Graves' disease. Of the latter, four were restudied after $2-8 \frac{1}{2}$ months of treatment. Table I lists the clinical and laboratory data obtained in the hyperthyroid patients.

Each individual was given an intravenous injection of 50 $\mu \mathrm{Ci}$ (approximately $2 \mu \mathrm{g}$ ) of sterile ${ }^{181} \mathrm{I}$-labeled $\mathrm{T}_{3}{ }^{1}$ in a $1 \%(\mathrm{w} / \mathrm{v})$ solution of human serum albumin. Significant thyroidal recycling of inorganic ${ }^{131}$ I liberated by the peripheral degradation of labeled hormone was prevented by the administration of Lugol's iodine ( 2 drops every $8 \mathrm{hr}$ ). In the hyperthyroid patients, large doses of methimazole (30 $\mathrm{mg}$ every $6 \mathrm{hr}$ ) were given in addition to Lugol's iodine. Throughout the study, $12-\mathrm{hr}$ urine collections were made and samples of blood were drawn twice daily, usually at 12-hr intervals.

The concentration of trichloroacetic acid (TCA)-precipitable ${ }^{131} \mathrm{I}$ in serum was determined as follows. To $1 \mathrm{ml}$ of serum was added carrier iodide and a few milligrams of propylthiouracil, followed by $1 \mathrm{ml}$ of cold $20 \%$ TCA. The resulting precipitate was washed twice with cold $5 \%$ TCA,

\footnotetext{
${ }^{1}$ Obtained from The Radiochemical Centre, Amersham, England. At the time of injection, this material was approximately $95 \%$ pure, as judged by filter paper chromatography, iodide being the sole detectable contaminant.
} 
TABLE I

Clinical and Laboratory Data Obtained in the Patients with Hyperthyroid Graves' Disease

\begin{tabular}{|c|c|c|c|c|c|c|c|}
\hline Patient & Age, Sex & Clinical features & State & Treatment & Serum BEI & BMR & Weight \\
\hline \multirow{3}{*}{1} & $y r$ & \multirow{3}{*}{$\begin{array}{l}\text { Diffuse goiter and } \\
\text { ophthalmopathy }\end{array}$} & & & $\mu \mathrm{g} / 100 \mathrm{ml}$ & $\%$ & $k g$ \\
\hline & \multirow[t]{2}{*}{$37, \mathrm{M}$} & & Thyrotoxic & & $>20$ & +84 & 52 \\
\hline & & & Treated & Methimazole for $5 \frac{1}{2}$ months & 2.0 & -13 & 66 \\
\hline \multirow[t]{2}{*}{2} & \multirow[t]{2}{*}{$26, \mathrm{~F}$} & \multirow{2}{*}{$\begin{array}{l}\text { Diffuse goiter and } \\
\text { ophthalmopathy }\end{array}$} & Thyrotoxic & & 11.4 & +67 & 40 \\
\hline & & & Treated & Methimazole for $8 \frac{1}{2}$ months & 4.4 & -6 & 47 \\
\hline \multirow[t]{2}{*}{$3^{*}$} & \multirow[t]{2}{*}{$23, \mathrm{~F}$} & \multirow{2}{*}{$\begin{array}{l}\text { Diffuse goiter and } \\
\text { ophthalmopathy }\end{array}$} & Thyrotoxic & & 4.2 & +49 & 48 \\
\hline & & & Treated & Methimazole for 2 months & 1.2 & -4 & 54 \\
\hline \multirow[t]{2}{*}{4} & \multirow[t]{2}{*}{$37, \mathrm{~F}$} & \multirow[t]{2}{*}{ Diffuse goiter } & Thyrotoxic & & 7.4 & & 58 \\
\hline & & & Treated & Methimazole for 7 months & 2.6 & & 66 \\
\hline 5 & $30, \mathrm{~F}$ & Diffuse goiter & Thyrotoxic & & 8.4 & & 48 \\
\hline 6 & $60, \mathrm{~F}$ & Multinodular goiter & Thyrotoxic & & 7.0 & +90 & 61 \\
\hline 7 & $32, \mathrm{~F}$ & Diffuse goiter & Thyrotoxic & & 11.0 & & 45 \\
\hline
\end{tabular}

BMR, basal metabolic rate.

* Although this patient had normal values for serum $\dot{B E I}$ and protein-bound iodine (PBI) $(6.0,6.8 \mu \mathrm{g} / 100 \mathrm{ml})$, she was clinically very toxic and had a serum $T_{3}$ value of $928 \mathrm{ng} / 100 \mathrm{ml}$, which is more than three times the mean value in our normal subjects.

dissolved in $2 \mathrm{~N}$ sodium hydroxide, and made up to a standard volume for counting. Sufficient counts were obtained to reduce the probable counting error at $72 \mathrm{hr}$ to a maximum of $5 \%$.

In each study, the declining concentration of TCAprecipitable ${ }^{131} \mathrm{I}$ in serum was plotted as a function of time. The regression coefficient for that part of the curve which appeared to conform to a single exponential function was calculated by the method of least squares and was used to calculate the fractional rate of $T_{3}$ turnover. The volume of distribution of $T_{3}$ was calculated by a method previously employed for assessing the volume of distribution of $T_{4}$ (13). This method is designed to correct for the disproportionate loss of administered ${ }^{131} \mathrm{I}$ before attainment of distribution equilibrium. The rate of clearance of $T_{3}$ was calculated as the product of the volume of distribution and the fractional rate of turnover. Data were not sufficiently numerous to permit analysis according to multicompartmental models.

The total concentration of $T_{3}$ in serum was measured according to the method of Sterling, Bellabarba, Newman, and Brenner (10). The absolute rate of $T_{3}$ disposal was calculated as the product of the total concentration of $\mathrm{T}_{3}$ in serum and the rate of $T_{3}$ clearance. The concentration of butanol-extractable iodine (BEI) in serum was measured by the method of Benotti and Pino (14). ${ }^{2}$

\section{RESULTS}

In the normal subjects and the hyperthyroid patients, only $64 \%$ and $61 \%$ respectively of the ${ }^{131} \mathrm{I}$ in serum was precipitable with TCA $12 \mathrm{hr}$ after injection of the ${ }^{181}$ I-labeled $T_{3}$; this proportion remained essentially constant through the next $48 \mathrm{hr}$ of study, averaging at $72 \mathrm{hr} 68 \%$ in the normal subjects and $71 \%$ in the hyperthyroid patients.

\footnotetext{
${ }^{2}$ Performed by the Boston Medical Laboratory, Boston, Mass.
}

Normal subjects. The volume of distribution and fractional rate of turnover of $T_{3}$ after attainment of distribution equilibrium were calculated from the data obtained during the period from 24 to $72 \mathrm{hr}$ after administration of the ${ }^{131} I$-labeled $T_{3}$. Verification that distribution equilibrium of the residual labeled $T_{3}$ had been attained by $24 \mathrm{hr}$ was obtained as follows. In each subject, values for TCA-precipitable ${ }^{131} \mathrm{I}$ in serum during the period from 24 to $72 \mathrm{hr}$ after injection of the labeled $T_{3}$ were expressed as a per cent of the $24 \mathrm{hr}$ value. The pooled data for the entire group were then used to calculate, by the method of least squares, regression coefficients for the periods $24-48$ and $24-72 \mathrm{hr}$. After $72 \mathrm{hr}$, the values for TCA-precipitable ${ }^{131} \mathrm{I}$ in serum were considered to be unreliable because of the low counting rates and the contribution thereto of the iodoprotein that arises as a product of $\mathrm{T}_{3}$ degradation $(6,15)$. As depicted in Fig. 1, the fractional turnover rates calculated from the regression coefficients for the periods $24-48$ and $24-72 \mathrm{hr}$ agreed closely. This indicated that a single exponential rate of disappearance had been present during this time; hence, distribution equilibrium of the residual labeled $\mathrm{T}_{3}$ had been attained. The kinetic values derived from the data obtained in each subject during the period from 24 to $72 \mathrm{hr}$ are presented in Table II. The mean value for the volume of $\mathrm{T}_{3}$ distribution was $43 \pm 2$ liters (mean $\pm \mathrm{SE}$ ) or 0.62 \pm 0.03 liter $/ \mathrm{kg}$, and for the fractional rate of $\mathrm{T}_{3}$ turnover, $52 \pm 5 \%$ per $24 \mathrm{hr}$. The calculated rates of $\mathrm{T}_{\mathrm{s}}$ clearance therefore averaged $22.3 \pm 2.1$ liters $/ 24 \mathrm{hr}$. Values for the total concentration of $T_{3}$ in serum averaged $273 \pm 23 \mathrm{ng} / 100 \mathrm{ml}$, and for the absolute rate of 
Ts disposal, $60 \pm 7 \mu \mathrm{g} / 24 \mathrm{hr}$. Calculated values for the fraction of injected ${ }^{121} \mathrm{I}$ ultimately appearing in the urine (urinary maximum) averaged $78 \pm 5 \%$ of the administered dose.

Hyperthyroid patients. In the patients with untreated hyperthyroidism, the individual disappearance curves of TCA-precipitable ${ }^{181} \mathrm{I}$ in serum drawn from data obtained during the period from 24 to $72 \mathrm{hr}$ appeared to deviate from a single exponential function. Consequently, as in the normal subjects, the data were pooled and regression coefficients for the periods $24-48$ and 24-72 $\mathrm{hr}$ were calculated (Fig. 1). The resulting pooled disappearance curve appeared to conform to a single exponential function from 24 to $48 \mathrm{hr}$, but thereafter the rate of disappearance of TCA-precipitable ${ }^{281} \mathrm{I}$ decreased. During the untreated thyrotoxic state, therefore, fractional rates of $T_{s}$ turnover were determined from the individual data obtained from 24 to $48 \mathrm{hr}$. In the studies performed after treatment, the calculated regression coefficients for the periods $24-48$ and 24-72 $\mathrm{hr}$ agreed closely. Nevertheless, both because of the relatively poor correlation of the 60 and $72 \mathrm{hr}$ points with the calculated regression line and for purposes of comparison with the untreated thyrotoxic state, fractional rates of $\mathrm{T}_{\mathrm{s}}$ turnover were determined from the individual data obtained only during the period from 24 to $48 \mathrm{hr}$.
Table II summarizes the data obtained. The mean value for the volume of $T_{3}$ distribution in the patients with untreated hyperthyroidism was $45 \pm 5$ liters or $0.91 \pm 0.13 \mathrm{liter} / \mathrm{kg}$. The value related to body weight was significantly greater than that in the normal subjects $(P<0.001)$. Treatment was followed by a decrease in the volume of $T_{3}$ distribution; this decrease was significant statistically, as judged from the paired $t$ test $(P<0.01)$. In the untreated patients, the mean value for the fractional rate of $\mathrm{T}_{3}$ turnover was $84 \pm 6 \%$ per $24 \mathrm{hr}$. This value was significantly greater than that obtained in the normal subjects $(P<0.01)$ and did not change appreciably after treatment. The mean value for the calculated rate of $\mathrm{T}_{3}$ clearance in the untreated patients was $36.7 \pm 3.7$ liters $/ 24 \mathrm{hr}$. This value was also significantly greater than that obtained in the normal subjects $(P<0.01)$. In the four patients studied before and after treatment, $T_{3}$ clearance rate decreased during treatment in all with the mean clearance rate changing from 38.7 to 24.5 liters/24 hr. This difference was statistically significant when corrected for body weight $(P<0.05)$. Values for the rate of $\mathrm{T}_{3}$ clearance in patients with treated hyperthyroidism were very similar to and did not differ significantly from those in the normal group, regardless of whether or not they were expressed in relation to body weight. In the untreated patients, the mean value for the total concentration of

NORMAL

THYROTOXIC

TREATED

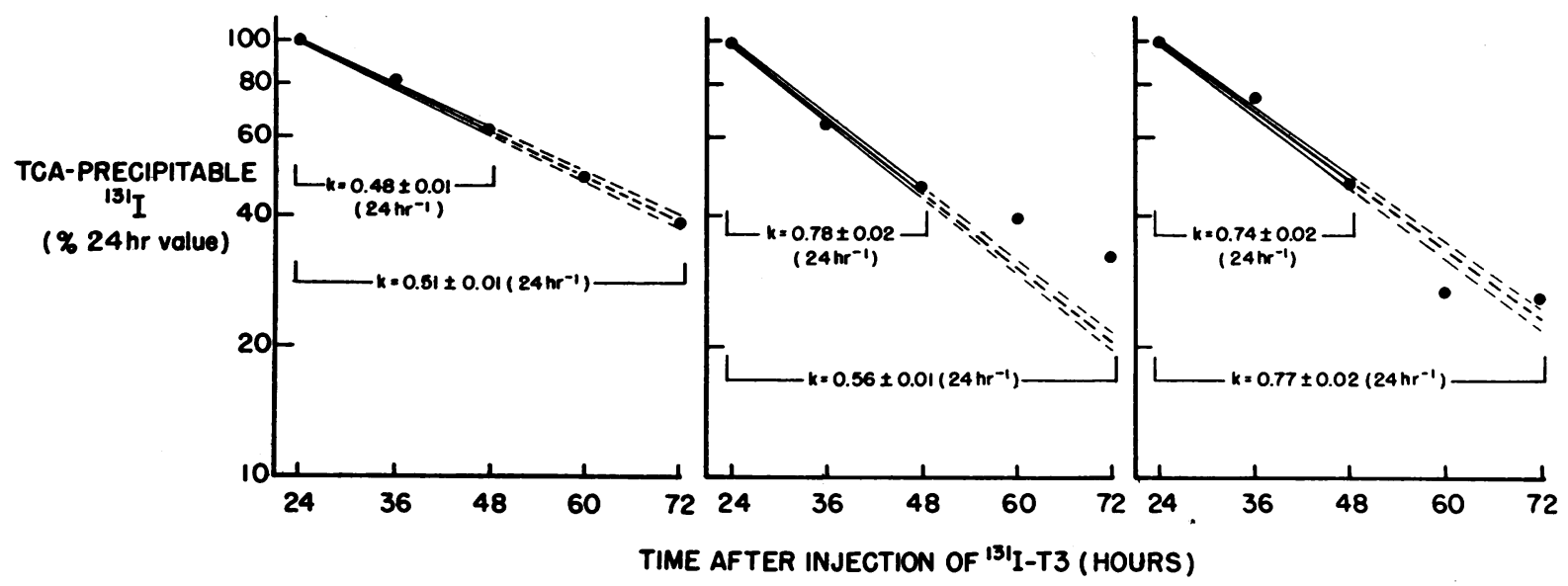

FIGURE 1 Pooled curves for the disappearance of trichloroacetic acid (TCA)-precipitable ${ }^{181} \mathrm{I}$ from serum after the administration of labeled $3,3^{\prime}, 5$-triiodo-L-thyronine $\left(T_{3}\right)$ to normal subjects and to patients with untreated and treated hyperthyroid Graves' disease. In each curve, the individual points are the mean of values obtained in individual subjects, expressed as a per cent of their individual $24-\mathrm{hr}$ values. In the normal subjects, the concentration of TCAprecipitable ${ }^{121} \mathrm{I}$ in serum at $24 \mathrm{hr}$ averaged $1.32 \%$ administered dose/liter, with a range of 1.13-1.76. The corresponding values in the patients with untreated and treated hyperthyroid Graves' disease were 0.96 (range, 0.59-1.31) and 1.33 (range, 1.09-1.85), respectively. The values for fractional turnover rate $(k)$ shown represent the mean \pm SE calculated by the method of least squares. The values shown are similar but not identical to those in Table II and the text since they were derived from the pooled data for each group. 
$T_{s}$ in serum was $912 \pm 94 \mathrm{ng} / 100 \mathrm{ml}$, and the absolute rates of $T_{3}$ disposal averaged $336 \pm 48 \mu \mathrm{g} / 24 \mathrm{hr}$, a value significantly greater than that found in the normal subjects $(P<0.001)$. In the treated patients, attempts were made to measure the total concentration of $T_{3}$ in serum, but a transient technical problem exhausted the small supply of serum. The values for urinary maximum varied widely in the untreated patients, did not differ significantly from those obtained in the normal subjects, and did not change in a consistent manner after treatment.

\section{DISCUSSION}

The increasing awareness of the likelihood that $T_{3}$ plays an important role relative to $T_{4}$ in overall thyroid hormone economy makes an appreciation of the kinetics of peripheral $T_{s}$ metabolism essential. Some data concerning this topic are available, but they are relatively scant and certain inconsistencies exist among them (1-8). Much of this conflict doubtless stems from difficulties in assessing accurately the distribution and turnover of the labeled hormone which result ultimately from its rapid peripheral metabolism. The first problem con-

TABLE II

The Kinetics of the Peripheral Metabolism of 3,3',5-Triiodo-L-Thyronine $\left(T_{3}\right)$ in Normal Subjects and in Patients with Hyperthyroid Graves' Disease Before and After Treatment

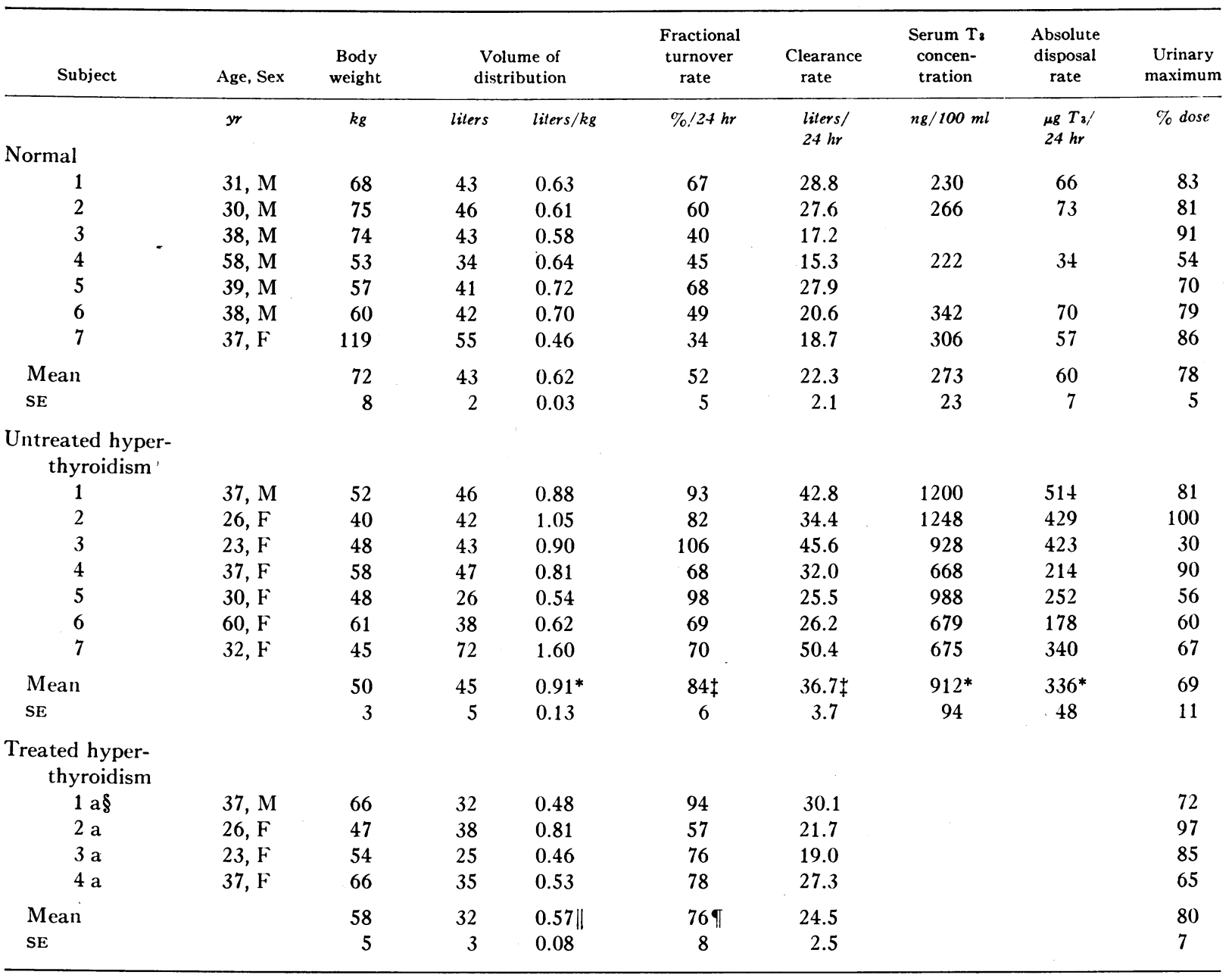

* Vs. normal subjects, $P<0.001$.

$\ddagger$ Vs. normal subjects, $P<0.01$.

$\S$ The letter "a" indicates that the patient is the same as the patient indicated by the same number in the untreated hyperthyroid group.

II Vs. thyrotoxic patients by paired $t$ test, $P<0.01$.

TI Vs. normal subjects, $P<0.05$. 
cerns the appearance in serum of labeled products of $\mathrm{T}_{3}$ degradation which tend to obscure the primary $T_{3}$ disappearance curve. The second problem concerns the question of whether distribution equilibrium has been attained during that period when accurate measurements of the concentration of residual labeled $T_{3}$ in serum are still possible.

The present study has demonstrated that radioiodide is a major degradative contaminant of the residual labeled $T_{3}$, constituting about one-third of the total radioactivity in serum during the period from 12 to $72 \mathrm{hr}$. Consequently, all the present data for serum represent values for TCA-precipitable, rather than total, ${ }^{131} \mathrm{I}$. A second product of $\mathrm{T}_{3}$ degradation is an iodoprotein which is butanol-insoluble and TCA-precipitable $(6,15)$. Since this material appears to turn over at a slower rate than. $T_{3}$, the question must be raised as to whether it has materially influenced the present estimates of the distribution and turnover of $\mathrm{T}_{3}$, which are based upon measurements of TCA-precipitable ${ }^{131} \mathrm{I}$. Two lines of evidence indicate that this is not the case in the normal subjects. The first is the close concordance that we have observed between the calculated regression coefficients for the periods 24-48 and 24-72 hr. Had the butanol-insoluble material exerted a significant influence, the regression coefficient calculated from the pooled data obtained from 24 to $72 \mathrm{hr}$ would have been significantly smaller than the corresponding value for the 24 to $48 \mathrm{hr}$ period. The second is the fact that, with one exception (1), previously reported values for the fractional rate of $T_{3}$ turnover, regardless of whether corrections were made for the butanol-insoluble radioiodine, agree remarkably well with those presented here (2-8). This close agreement is all the more remarkable when considered in light of the fact that in one study (3) the values obtained were derived from whole body counting whereas in the present study as well as the remaining previous studies $(2,4-8)$, the values were derived from data analyzed according to a single compartmental model, indicating that the error introduced by this type of analysis is minimal.

In the normal subjects, concordance of the calculated regression coefficients for the 24-48 and 24-72 hr periods also indicated that the administered labeled $\mathrm{T}_{3}$ had attained virtually complete distribution equilibrium by $24 \mathrm{hr}$. Stronger evidence that distribution equilibrium of labeled $\mathrm{T}_{3}$ is attained by $24 \mathrm{hr}$ is provided by data obtained by the method of Nicoloff and Dowling (16). Nicoloff has found that when a dose of radioiodinelabeled $T_{3}$ is administered and allowed to equilibrate and is then followed by a second pulse of $T_{3}$ labeled with a different radioisotope of iodine, the ratio of the two isotopes in the urine becomes constant between 12 and
$17 \mathrm{hr}^{3}$ This period is the time required for the second pulse to attain distribution equilibrium.

Reported values for the volume of distribution of $\mathrm{T}_{3}$ vary widely, but in general they are several-fold larger than those for $T_{4}$, probably owing to the much weaker binding of $T_{3}$ than of $T_{4}$ in serum (17). With respect to $\mathrm{T}_{3}$, mean values as low as 18.1 and 22.8 liters have been reported $(4,5)$. In contrast are the present values which averaged 43 liters, and those reported by Surks and Oppenheimer which averaged 38.1 liters (6). In one remaining study, values for the volume of $T_{3}$ distribution were derived from whole body counting and averaged 31 liters (3); however, if this value were corrected for the proportion of TCA-soluble radioactivity that we have found, a value of approximately 46 liters would result. We are unable to account for the discrepancies between these two groups of observations.

The present study appears to be the first in which conjoint measurements of the rate of $T_{3}$ clearance and the total concentration of $\mathrm{T}_{3}$ within the pool, and hence the absolute rate of $T_{3}$ disposal, have been made in the same individual. In the normal subjects, values for the absolute rate of $\mathrm{T}_{3}$ disposal averaged $60 \mu \mathrm{g} / 24 \mathrm{hr}$, a figure not greatly different from the approximately 80 $\mu \mathrm{g}$ of $\mathrm{T}_{4}$ which is turned over daily in the normal individual (13). It should not be concluded, however, that these values necessarily represent the relative rates of secretion of the two hormones from the thyroid gland since recent evidence indicates that a substantial quantity of $T_{3}$ arises from $T_{4}$, at least when the latter is given orally (18). For the same reason, it is not justifiable to draw inferences concerning the relative metabolic contributions of the $T_{4}$ and $T_{3}$ secreted by the thyroid gland.

The problems encountered in analyzing curves of the disappearance of $\mathrm{T}_{3}$ from serum were accentuated in the patients with untreated hyperthyroidism. Unlike the case in the normal subjects, curves for the disappearance of TCA-precipitable ${ }^{131} \mathrm{I}$ from serum did not conform to a single exponential function after $48 \mathrm{hr}$. This might be due to the greater relative contribution of the butanol-insoluble ${ }^{131} \mathrm{I}$ to the total TCA-precipitable radioactivity. Hence, it was necessary to estimate the fractional rate of $T_{3}$ turnover from data obtained during the period from 24 to $48 \mathrm{hr}$ after administration of the labeled $\mathrm{T}_{3}$. Although estimates of the fractional rate of turnover based on such a short period of observation are less than ideal, the very rapid rate of turnover tends to increase their accuracy since one half-life could be observed during the $24 \mathrm{hr}$ period.

In the present study, the fractional rate of $T_{3}$ turnover was greatly increased in the hyperthyroid patients,

\footnotetext{
${ }^{3}$ Nicoloff, J. T. Personal communication.
} 
a change similar to that previously reported for $\mathrm{T}_{4}$ (13). This cannot be ascribed to inclusion of the butanol-insoluble ${ }^{181} \mathrm{I}$ in the TCA-precipitable radioactivity in serum since this would retard rather than accelerate the disappearance curve. The increase in the fractional rate of turnover is in all likelihood owing to an increase in the activity of intracellular mechanisms for $T_{3}$ metabolism. It cannot be ascribed solely to hypermetabolism since it tends to persist after the hyperthyroidism has been treated. Furthermore, it cannot be ascribed to an increase in the serum $T_{4}$ concentration per se since an acute increase in serum $T_{4}$ concentration induced by a $T$, load decreases rather than increases the fractional rate of $T_{3}$ turnover (19). In untreated hyperthyroidism, the volume of $T_{3}$ distribution was also increased when related to body weight. This increase was, in all likelihood, owing to an increased degree of saturation of thyroxine-binding globulin (TBG) resulting from the increased total concentrations of $T_{4}$ and $T_{3}$ in serum and the decreased binding capacity of TBG (20, 21). As a result of these changes, the calculated rate of $\mathrm{T}_{3}$ clearance was greatly increased. A very pronounced increase in the total concentration of $T_{3}$ in serum was also seen. Relative to normal values, this increase was disproportionately greater than that for $T_{4}$, as judged from measurements of the BEI, in the same patients. The absolute daily rate of $T_{3}$ disposal averaged $336 \mu \mathrm{g}$, a value more than five times the normal. It is uncertain whether this increase in daily disposal is relatively greater than that observed in the case of $T_{4}$, and hence, whether $T_{3}$ contributes disproportionately to the maintenance of the hyperthyroid state. This question could best be answered by studying the simultaneous turnover of both hormones in a single group of patients.

After treatment, the volume of $T_{3}$ distribution returned to normal, reflecting, in all likelihood, the combination of a decrease in the total concentrations of $T_{4}$ and $T_{3}$ and an increase in the binding capacity of TBG in serum (21). By contrast, the increase in the fractional rate of turnover. persisted after treatment, despite the attainment of a normal metabolic state. This persistent abnormality in the peripheral metabolism of $\mathrm{T}_{3}$ is reminiscent of that previously observed for $T_{4}$ in treated hyperthyroidism $(22,23)$ and indicates that the acceleration of hormonal turnover in hyperthyroidism is not due solely to the hypermetabolism per se.

\section{ACKNOWLEDGMENTS}

This work was supported in part by Research Grants AM-09753 and AM-10739 from the National Institute of Arthritis and Metabolic Diseases, and by Grant FR-76 from the Division of Research Facilities and Resources, National Institutes of Health, Bethesda, Md.

\section{REFERENCES}

1. Sterling, K., J. C. Lashof, and E. B. Man. 1954. Disappearance from serum of $\mathrm{I}^{131}$-labeled $\mathrm{L}$-thyroxine and L-triiodothyronine in euthyroid subjects. J. Clin. Invest. $33: 1031$.

2. Wiswell, J. G., and V. Coronho. 1962. Disappearance of $\mathrm{I}^{181}$-triiodothyronine from the plasma in the presence of fever. J. Clin. Endocrinol. Metab. 22: 657.

3. Fisher, D. A., and T. H. Oddie. 1964. Whole-body counting of ${ }^{181} \mathrm{I}$-labeled triiodothyronine. J. Clin. Endocrinol. Metab. 24 : 733.

4. Gregerman, R. I., and N. Solomon. 1967. Acceleration of thyroxine and triiodothyronine turnover during bacterial pulmonary infections and fever: implications for the functional state of the thyroid during stress and in senescence. J. Clin. Endocrinol. Metab. 27: 93.

5. Mirouze, J., C. Jaffiol, R. Pastorello, and L. Baldet. 1967. Nouvelle technique d'étude du métabolisme des hormones thyroidiennes $\left(\mathrm{T}_{\mathbf{4}_{125}}-\mathrm{T}_{\mathbf{3 1 3 1}_{13}}\right)$ données expérimentales et cliniques. Ann. Endocrinol. 28: 445.

6. Surks, M. I., and J. H. Oppenheimer. 1969. Formation of iodoprotein during the peripheral metabolism of $3,5,3^{\prime}-$ triiodo-L-thyronine- ${ }^{125} \mathrm{I}$ in the euthyroid man and rat. J. Clin. Invest. $48: 685$.

7. Zaninovich, A. A., R. J. Soto, R. Volpé, and C. Ezrin. 1967. The peripheral interaction of $T_{4}$ and $T_{3}$ in estrogen treated human subjects. Abstracts of the American Thyroid Association. 37.

8. Zaninovich, A. A., R. J. Soto, R. Volpé, and C. Ezrin. 1968. Effects of androgens and diphenylhydantoin (DPH) on the late phase of $T_{3}$ disappearance from the circulation. Excerpta Med. Int. Congr. Ser. 157: 474. (Abstr.)

9. Nauman, J. A., A. Nauman, and S. C. Werner. 1967. Total and free triiodothyronine in human serum. J. Clin. Invest. 46: 1346.

10. Sterling, K., D. Bellabarba, E. S. Newman, and M. A. Brenner. 1969. Determination of triiodothyronine concentration in human serum. J. Clin. Invest. 48: 1150.

11. Hollander, C. S. 1968 . On the nature of the circulating thyroid hormone: clinical studies of triiodothyronine and thyroxine in serum using gas chromatographic methods. Trans. Ass. Amer. Physicians Philadelphia. 81: 76.

12. Hales, I. B., and B. M. Dobyns. 1960 . The metabolism of triiodothyronine in Graves' disease. J. Clin. Endocrinol. Metab. 20: 68.

13. Ingbar, S. H., and N. Freinkel. 1955. Simultaneous estimation of rates of thyroxine degradation and thyroid hormone synthesis. J. Clin. Invest. 34: 808.

14. Benotti, J., and S. Pino. 1966. A simplified method for butanol-extractable iodine and butanol-insoluble iodine. Clin. Chem. 12 : 491.

15. Brown-Grant, K. 1967. Further studies of the metabolism of thyroxine and 3,5,3'-triiodothyronine in the guinea pig. J. Physiol. (London). 191: 167.

16. Nicoloff, J. T., and J. T. Dowling. 1968. Estimation of thyroxine distribution in man. J. Clin. Invest. 47: 26.

17. Ingbar, S. H., L. E. Braverman, N. A. Dawber, and G. Y Lee. 1965. A new method for measuring the free thyroid hormone in human serum and an analysis of the factors that influence its concentration. J. Clin. Invest. 44: 1679 . 
18. Braverman, L. E., S. H. Ingbar, and K. Sterling. 1969. In vivo conversion of thyroxine $\left(T_{4}\right)$ to triiodothyronine $\left(\mathrm{T}_{3}\right)$ in man. Abstracts of the 51st Meeting of the Endocrine Society. 75.

19. Woeber, K. A., E. Hecker, and S. H. Ingbar. 1969. The effects of an acute load of thyroxine on the transport and peripheral metabolism of triiodothyronine in man. J. Clin. Invest. 49: 650 .

20. Inada, M., and K. Sterling. 1967. Thyroxine transport in thyrotoxicosis and hypothyroidism. J. Clin. Invest. 46: 1442.
21. Braverman, L. E., A. E. Foster, and S. H. Ingbar. 1968. Thyroid hormone transport in the serum of patients with thyrotoxic Graves' disease before and after treatment. J. Clin. Invest. 47 : 1349.

22. Ingbar, S. H., and N. Freinkel. 1958. Studies of thyroid function and the peripheral metabolism of $\mathrm{I}^{181}$-labeled thyroxine in patients with treated Graves' disease. $J$. Clin. Invest. 37: 1603.

23. Nicoloff, J. T., and J. T. Dowling. 1968. Studies of peripheral thyroxine distribution in thyrotoxicosis and hypothyroidism. J. Clin. Invest. 47: 2000. 